\title{
Acquisition of the Verb Movement Parameter in French by Adult English Speakers
}

Sri Lanka Journal of Social Sciences and Humanities Volume 2 Issue 1, February 2022: 11-20 ISSN: 2773 692X (Online), 27736911 (Print) Copyright: (C) 2021 The Author(s)

Published by Faculty of Social Sciences and Languages, Sabaragamuwa University of Sri Lanka Website: https://www.sab.ac.lk/sljssh DOI: http://doi.org/10.4038/sljssh.v2i1.52

\author{
Gunawardena, C.P. ${ }^{1, *}$ \\ 1 University of Kelaniya, Dalugama, 11600, Sri Lanka.
}

Received: 05 March, 2021, Revised: 16 September, 2021, Accepted: 06 November, 2021.

How to Cite this Article: Gunawardena, C.P. (2022). Acquisition of the verb movement parameter in French by adult English speakers. Sri Lanka Journal of Social Sciences and Humanities, 2(1), 11-20.

\begin{abstract}
This paper focuses on a parametric difference between French and English, namely the verb movement parameter. Previous research shows that verb-raising in French causes learnability problems for Anglophone learners. Because of verb raising in French, an adverb may be placed between the verb and its direct object, allowing the subject-verb-adverb-object (S-V-Adv-O) structure. However, the lack of verb movement prohibits the S-V-Adv-O structure in English. The acquisition of verb movement is a welldocumented topic in the second language (L2) acquisition research. However, previous L2 acquisition studies have focused on L2 speakers who are in the initial stage of their $L 2$ acquisition. The present paper focuses on the acquisition of the verb movement parameter by a group of intermediate L2 French speakers whose first language (L1) is English. It also investigates two models, namely the Failed Functional Features Hypothesis (FFFH) and the Full Transfer Full Access Hypothesis (FTFAH). The FFFH predicts that L2 speakers are unable to reset parameters from their L1 values to the L2 settings, as they do not have access to Universal Grammar (UG). On the contrary, the FTFAH suggests that $L 2$ speakers can reset parameters to the target $L 2$ settings due to the full accessibility of UG. The data was collected via three tasks: an acceptability judgment task, a preference task, and a production task. The findings suggest that the L1-English-L2-French speakers had not fully acquired the adverb placement in French. Therefore, the results support the FFFH, as the L1-English-L2-French speakers had not reset parameters from their L1 values to the L2 settings.
\end{abstract}

Keywords: French, L2 learners, Verb movement parameter

\section{INTRODUCTION}

The key goal of the present paper is to shed light on grammar development in the second language (L2) acquisition. This goal is achieved through a study of $L 2$ speakers whose first language (L1) is English. The present paper examines the availability of Universal Grammar (UG) in L2 acquisition. Studies on $\mathrm{L} 2$ acquisition do not report converging evidence regarding the debate in the field, which concerns whether adult $\mathrm{L} 2$ learners can reset parameters, and still have access to (UG) (Rogers, 2009; White, 2003; Adger, 2003; Marsden, Whong \& Gil, 2018). UG is an influential theory, which was postulated by Noam Chomsky in the 1950s. According to Chomsky, UG is an innate endowed language faculty equipped with abstract principles of grammar and parameters (Chomsky, 1989). Parameters are an important aspect of language acquisition, and the similarities and differences between languages are often argued to fall out from parameters of UG (White, 1991; White, 2003; Adger, 2003). Further, studies on $L 2$ acquisition do not always report converging evidence regarding whether $L 2$ speakers have full access to UG (Rogers, 2009; White, 2003, 1991; Adger, 2003; Marsden et al., 2018). Some researchers argue that L2 speakers have no access to UG, and they are unable to reset parameters in their L2 acquisition process (Clahsen, 1988; Meisel, 1991, 1997), whereas others maintain that L2 speakers have full access to UG, and they can reset parameters from their L1 value to the L2 setting (Eubank, 1994; Schwartz \& Sprouse, 1996; Vainikka \& Young-Scholten, 1996; BleyVroman, 1998; Clahsen \& Muysken, 1986, White, 2003).

The present paper tests two competing hypotheses (Failed Functional Features Hypothesis and Full Transfer Full Access Hypothesis), which make different predictions regarding the resetting of parameters in $\mathrm{L} 2$ acquisition. The Failed Functional Features Hypothesis (FFFH) maintains that $L 2$ speakers do not have access to UG, and they fail to reset parameters in L2 acquisition after the critical period (Hawkins \& Chan, 1997). On the other hand, the Full Transfer Full Access Hypothesis (FTFAH) claims that L2 speakers have access to UG, and they can reset parameters after the critical period (Schwartz \& Sprouse, 1994). More details about parameters and their influence on L2 acquisition are given later in the paper.

This paper focuses on parameter resetting in L2 French acquisition. In the next section, the adverb placement in French and English will be discussed concerning parameter settings.

\section{Adverb placement in English and French}

The adverb placement in French and English is relatively free. Both languages allow adverbs in pre-subject position as

\footnotetext{
* Corresponding author: Tel.: +94 70481 0549; Email: chandeera@kln.ac.lk (iD) https://orcid.org/0000-0003-2586-4051
} 
in (1) and (2) and at the end of the VP as in (3) and (4). However, French and English show certain contrasts regarding adverb placement. In English, adverbs may appear between the subject and the finite verb as in (5). However, English does not allow adverbs between the finite verb and the direct object as in (6), whereas in French, they may, as can be seen in (7). As illustrated in (8), in French, adverbs may not intervene between the subject and the finite verb, unlike in English. The similarities and differences between French and English illustrated in (5-8) are argued to fallout from a parameter of UG which links a cluster of properties (adverb placement, negation, object clitics) in each language (Adger, 2003; White, 1991). The verb movement parameter is discussed in the next section.

il lit

son roman.

2. Slowly, he reads his novel

3. 'Slowly he reads his novel.'

4. Slowly, he reads his novel.

5. II lit son roman lente-

ment.

6. he

$\begin{array}{ll}\text { reads } & \text { his } \\ \text { novel } & \text { slowly }\end{array}$

7. 'He reads his novel slowly.'

8. He reads his novel slowly.

9. Pierre often watches TV
10. *Pierre watches often TV.

11. Pierre regarde souvent la télé.

12. Pierre watches often the TV

13. 'Pierre often watches TV.'

14. *Pierre souvent regarde la télé.

15. Pierre often watches the TV

16. 'Pierre often watches TV.'

\section{Verb movement parameter in French and English}

The difference between French and English regarding adverb placement has been studied by several syntacticians (Emonds, 1978; Pollock, 1989; Chomsky, 1989). For the present paper, I will focus on the account by Adger (2003), who recounts verb movement in French. Adger (2003) explains that when [uInfl:] on $v$ is valued by $T$, [uInfl] is always strong in French. To satisfy the strong [uInfl] $v$ moves to T as in (9). However, in English, when [uInfl] on $v$ is valued by $\mathrm{T}$, [uInfl] is always weak. As a result, $v$ does not move to $T$ as in (10). How does the verb movement affect the position of adverbs in French and English? In French, when v moves to T in order to check strong features of [ulnfl], the finite verb ends up preceding the adverb as in (11). In English, $v$ does not move to $T$ in order to check features of [ulnfl], and as a result, the lexical verb does not precede an adverb as in (12) (Emonds, 1978; Pollock, 1989; Chomsky, 1989; Adger, 2003).

(9)

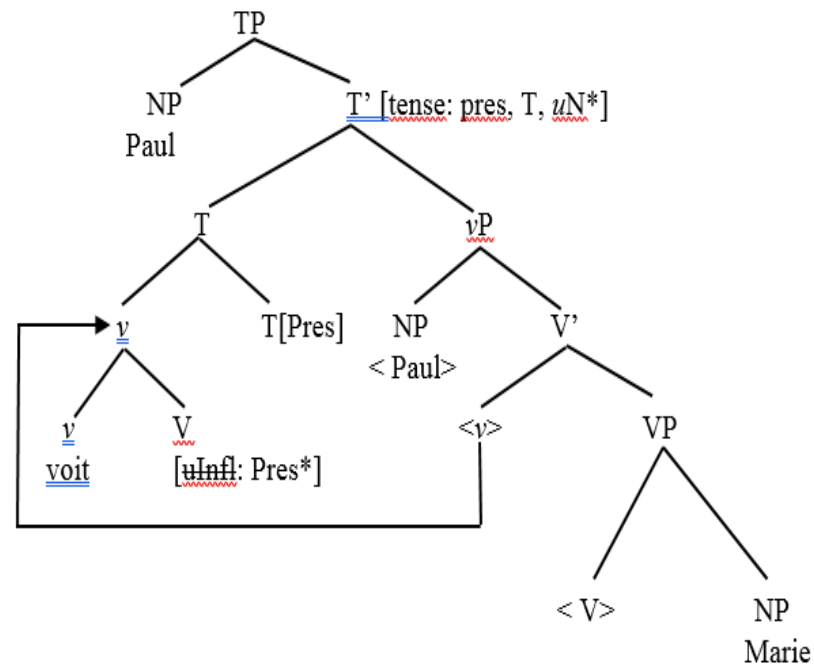

(10)

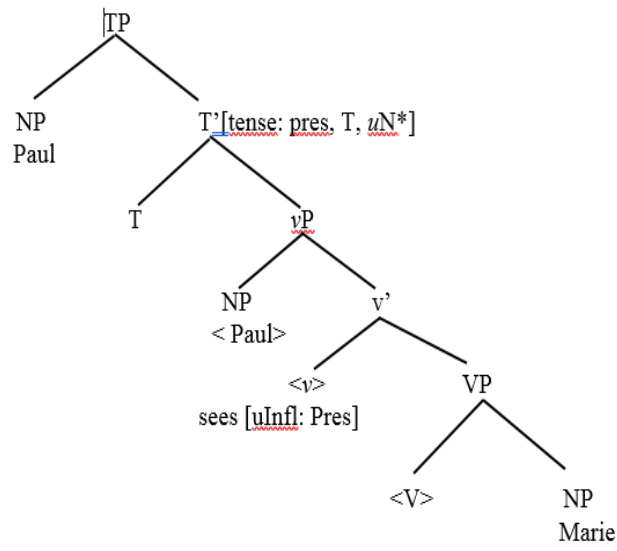


(11)

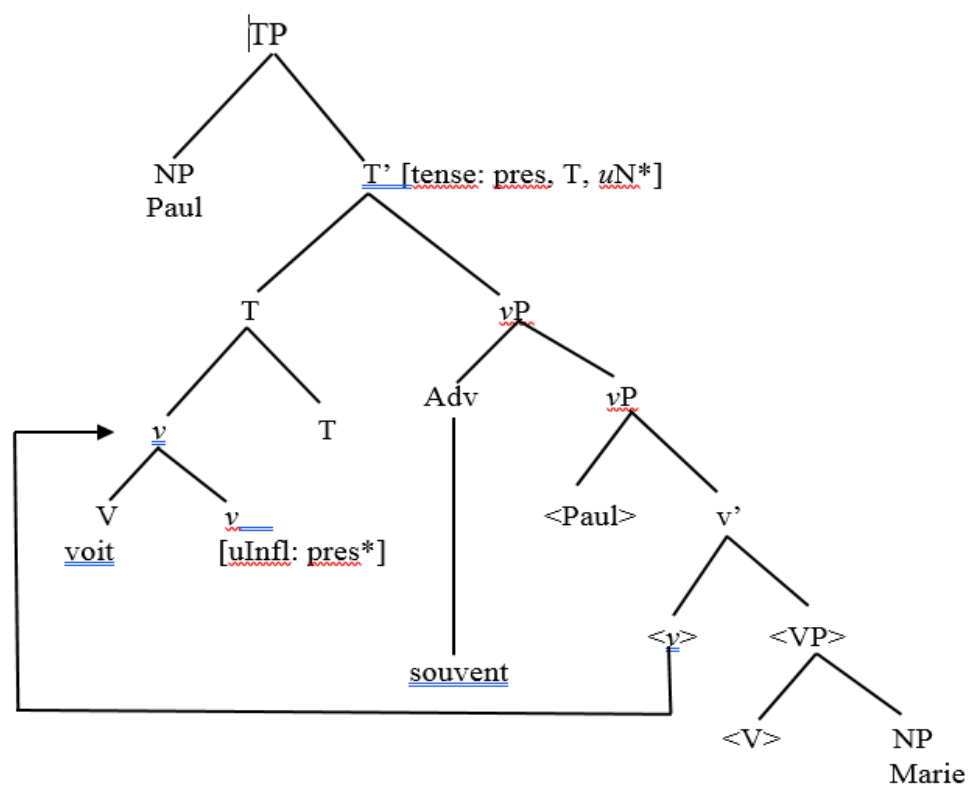

(12)

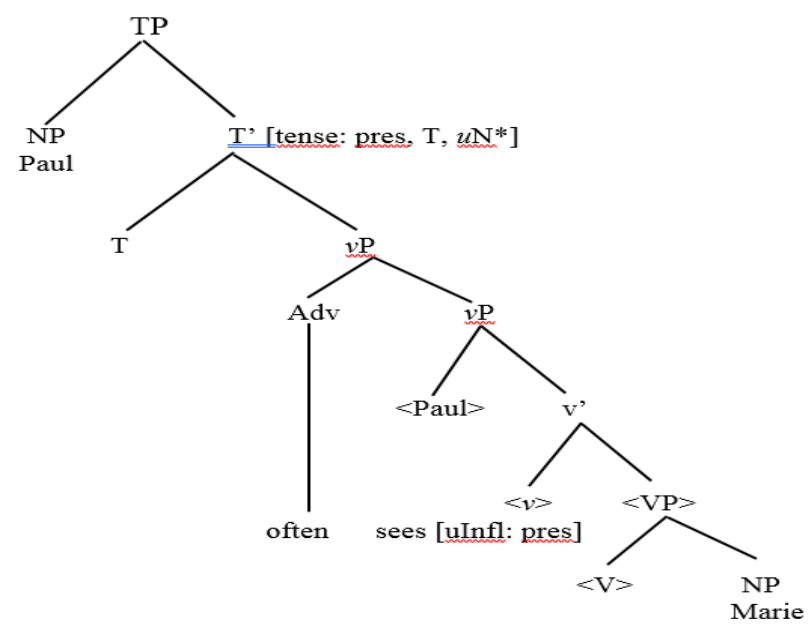

In sum, English is a language with weak inflection and lexical verbs cannot raise from the base position to the head of TP; therefore, the S-V-Adv- $\mathrm{O}^{2}$ The structure is ungrammatical in English. However, the same structure is grammatical in
French as verbs obligatorily raise from $\mathrm{V}$ to $\mathrm{T}$. Table 1 summarizes the word order in relation to the adverb placement in French and English.

Table 1. Word order in French and English (adverb placement)

\begin{tabular}{cccc}
\hline Word order & French & English & \\
\hline S-Adv-V-O & $\times$ & & $\checkmark$ \\
S-V-Adv-O & $\times$ & $\times$ & \\
\hline
\end{tabular}

\section{Learnability and parameter resetting in L2 acquisi-} tion

As mentioned previously, the present paper is concerned with native speakers of English learning French. Their L1 does not instantiate the verb-raising value of the parameter discussed above. However, their L2 French allows verb-raising. Therefore, L1-English-L2-French speakers need to reset their L1 parameter in L2 French acquisition. Moreover, L1English-L2-French speakers must discover that French does not allow *S-Adv-V-O structure as in (13). The next section presents two seminal L2 acquisition studies which investigate
(13) *Pierre
souvent regarde
la télé
Pierre often
watches the
TV

'Pierre often watches TV.'

\section{LITERATURE REVIEW}

One of the seminal studies on adverb placement was done by White (1991). She investigated knowledge of adverb placement in L2 English by native French speakers. Two L2

\footnotetext{
${ }^{2}$ subject-verb-adverb-object structure
}

${ }^{3}$ subject-adverb-verb-object structure 
groups took part in the study. The first group received instruction on adverb placement (adverb group), and the other group was taught how to form questions (question group) in English. There were 82 participants in the adverb group, whereas, in the question group, there were 52 participants. The data was collected via three tasks: an acceptability judgment task, a preference task, and a manipulation task. The three tasks tested the following word orders: SAdv-V-O, *S-V-Adv-O, Adv-S-V-O, and S-V-O-Adv. As we noted previously, the adverbs are placed post verbally in French, but not in English, which means that the S-V-Adv-O order is ungrammatical in English. Therefore, White (1991) predicted that the French-speaking L2 English learners would accept *S-V-Adv-O order in English due to transfer from their L1 French. The participants were tested on different occasions: they were pretested and post-tested twice, immediately after the instruction period, and again five weeks later. A follow-up study was also conducted one year after the experiment. In the pre-test, the adverb group and question group accepted both grammatical and ungrammatical structures (S-Adv-V-O and *S-V-Adv-O). However, in the post-tests, there was an apparent difference between the adverb group and the question group. The adverb group was more target-like than the question group on the adverb placement. According to the author, the difference between the groups suggests that explicit instructions help L2 French learners to acquire target properties in English. In the followup study, both groups again accepted both grammatical and ungrammatical word orders in English.

Rogers (2009) investigated knowledge of negation, adverb placement, subject clitics, and object clitics in L2 French. Though here, I focus only on the results for adverb placement. The data was collected from seventy-five L1-EnglishL2-French speakers who were at different proficiency levels: beginner, low-intermediate, high-intermediate, low-advanced and high-advanced. There were fifteen participants in each group. The $L 2$ speakers were divided into different groups considering the length of instruction in French. Ten L1 French speakers served as a control group. The data was collected via an oral production task, a comprehension task, an acceptability judgement task. In the oral production task, the French native speakers predominantly used the S-V-Adv$X$ order. However, unlike the native speakers, the non-native speakers did not use S-V-Adv-X order predominantly in their production. The high-advanced group had $30 \%$ use of this structure, whereas all the other groups, use that structureless frequently (less than $20 \%$ ). The results of the comprehension task showed that knowledge of adverb placement increases with the French proficiency of the learners. In the acceptability judgement task, the beginner group's rejection rate of ungrammatical word order was at $45 \%$, and with a $48 \%$ of rejection rate of ungrammatical order, the low-intermediate group did not differ significantly from the beginner group. The rejection rates of ungrammatical word order for low advanced and high-advanced groups were similar $(41 \%$ and $40 \%$ ) respectively. As the author expected, in the acceptability judgement task, the acceptance of the ungrammatical word order (S-Adv-V-X) decreases with French proficiency. The overall results suggest that adverb placement seems to be problematic for all groups.

\section{RESEARCH QUESTIONS AND HYPOTHESES}

Considering the cross-linguistic difference between French and English, I planned the following research questions and hypotheses. As indicated previously, the present paper tests two competing models: the FFFH and the FTFAH. The research questions and hypotheses are formulated in relation to these two models.

Research Question 1:

What are the characteristics of adverb placement in L2 French by L1-English speakers?

\section{Research Question 2:}

To what extent can either the FFFH and the FTFAH account for L2 French characteristics?

Hypothesis 1: L2 French adverb placement under the FFFH As explained previously, English does not allow the S-V-Adv$\mathrm{O}$ structure, whereas, in French, the S-V-Adv-O structure is grammatical. Therefore, if the FFFH is correct, then the L1English-L2 French speakers will assume that the L1 parameter settings are appropriate for their $\mathrm{L} 2$, and they will reject the grammatical S-V-Adv-O structure in French. On the contrary, they will accept the ungrammatical S-Adv-V-O structure in French.

\section{Hypothesis 2: L2 French adverb placement under the FTFAH}

If the FTFAH is correct, then the L1-English-L2 French speakers will reset the $\mathrm{L} 1$ parameters, and they will reject the ungrammatical S-Adv-V-O structure in French. Under the verbraising value of the parameter, they will accept the grammatical S-V-Adv-O structure in French.

\section{METHODOLOGY}

\section{Participants}

Twenty participants took part in the study. The research design included an experimental group and a control group. The experimental group included twelve L1-English-L2 French speakers (hereafter non-native speakers). The nonnative speakers were upper-intermediate speakers of French. The control group had eight L1-French speakers (hereafter native speakers). The participants were recruited from the University of York, UK. The non-native speakers were undergraduate students, whereas the native speakers were visiting students from France.

\section{Experimental materials}

The experiment included three tasks: an acceptability judgement task, a preference task, and a production task. Three different tasks were devised to test the knowledge of French adverb placement. Both the native and non-native speakers completed the three tasks. Three different tasks were devised to test the knowledge of French adverb placement. The three tasks covered four frequency adverbs: souvent 'often', toujours 'always', régulièrement 'regularly' and fréquemment 'frequently'.

\section{Acceptability Judgement task (AJT)}

The written AJT included thirty experimental tokens and twenty fillers. The thirty experimental tokens were divided equally (15 grammatical and 15 ungrammatical). The AJT tested the grammaticality contrast between S-V-Adv-O and *S-Adv-V-O. The grammatical tokens focused on the S-VAdv-O structure as in (14), whereas the ungrammatical tokens tested the *S-Adv-V-O structure as in (15). Twenty fillers were divided equally (10 grammatical and 10 ungrammatical). The fillers focused on object clitics as in (16) and (17). The AJT was built in PsychoPy. v3.0 (Pierce, 2007). Each experimental token and filler comprised a two-person brief dialogue in French. One person replies to a question that the other person asks by focusing on the adverb. The questions in the dialogues were presented in black on a grey screen, as 
in figure (1). The answers were presented in red on a grey screen, as in figure (2). The participants were asked to judge the acceptability of the statements given by the second person in the dialogues. The judgments of the participants were measured on a five-point Likert scale of -2 to +2 , where -2 means completely unacceptable, and 2 means perfectly acceptable. Table 2 summarises the design of the AJT.

Figure 1. Written AJT: A question of a test item

Quand est-ce que Simon fait ses devoirs ?

Figure 2. Written AJT: An answer to a test item

Il fait toujours ses devoirs le matin.

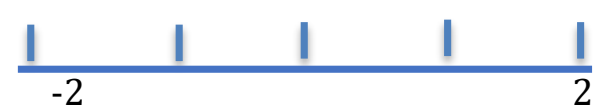

Table 2. The AJT design

Grammaticality $\quad$ Word order $\quad$ Examples $\quad \mathrm{N}$

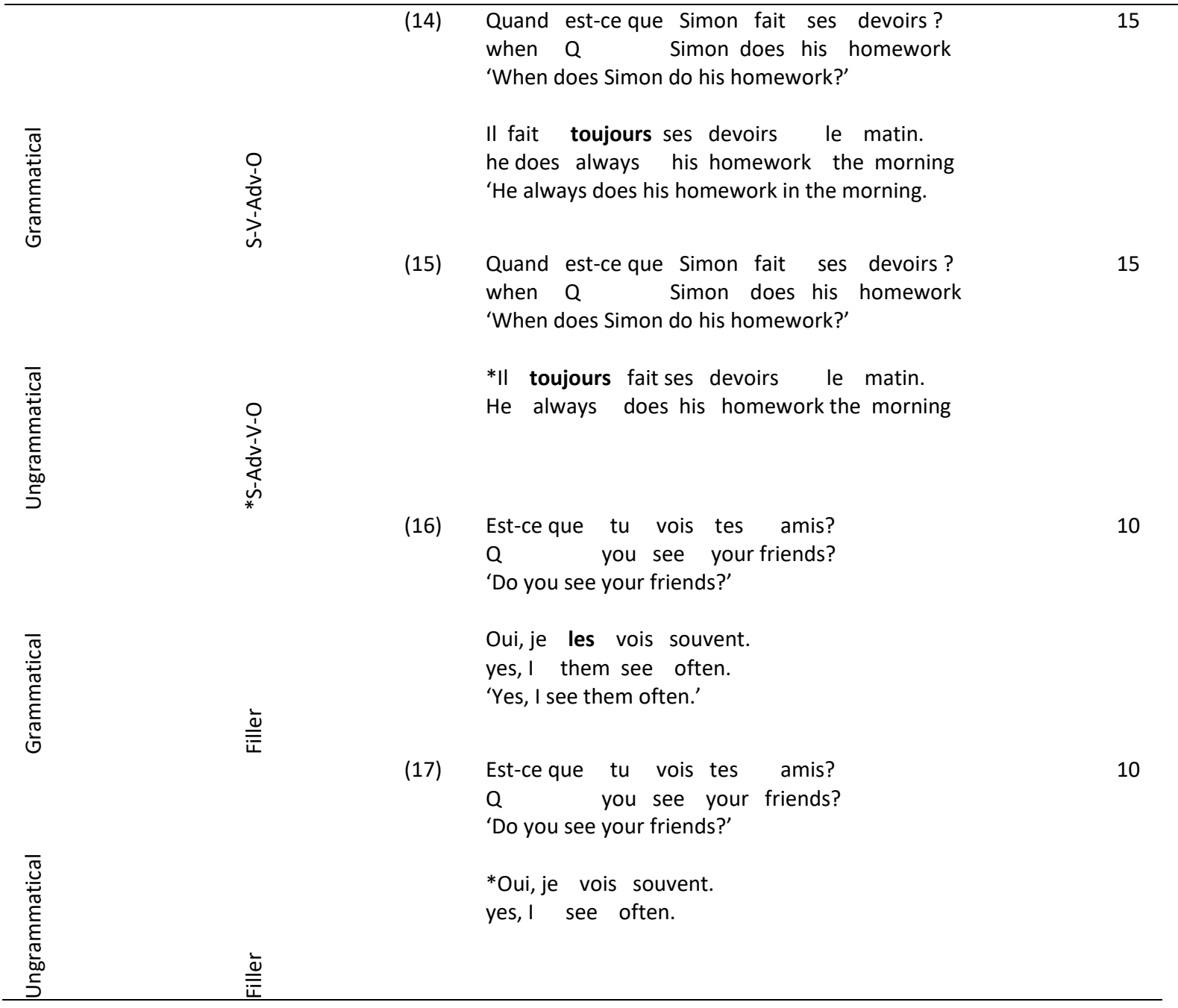

\section{Preference Task}

The second task was a preference task. The tokens in this task tested: *S-Adv-V-O and S-V-Adv-O structures. This task comprised twenty experimental tokens and ten fillers. The average display time for each token and filler was ten sec- onds. The participants were presented with two-person dialogues on a screen. Contrary to the previous task, the participants were presented with two versions of the second person's response: version $a$ ) and $b$ ) as in (18). The two versions differed only in syntactic form. The participants were asked to choose the version that they prefer. However, the answer 
grid was organised in a way that the participants could select other answers. The answer grid provided freedom for the participants to accept or reject both versions, and they could Table 3. The preference task design. also mention that versions ( $a$ ) and (b) were not relevant. Fillers focused on object clitics as in (19). Table 3 summarises the design of the preference task.

(18) Est-ce que Pierre regarde la télé le soir ? Q Pierre see-PRS the TV the evening 'Does Pierre watch TV in the evening?

Oui, il regard toujours la télé le soir yes he see-PRS always the TV the evening 'Yes, he always watches TV in the evening'

b) Oui, il toujours regard la télé le soir yes he always see-PRS the TV the evening

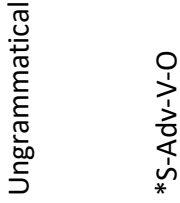
'Yes, he always watches TV in the evening'

(19) Est-ce que tu lis le journal ?

'Do you read the newspaper?'

Oui, je le lis yes, I it read

'Yes, I read it.'

b) Oui, je lis

yes, I read

'Yes, I read.'

\section{Production Task}

The ending task was a production task where the participant had to create a sentence with different adverbs. The participants were asked to do a role play with the researcher, and they were tested individually. The researcher posed questions to the participants, and they had to answer the questions using a set of cards (as in 20). Each adverb was tested with a different set of cards. When they answered the questions, they were asked if they could make another sentence with the same set of cards until they could do no more. The total number of tokens was six. The fillers were not included in the task. The researcher audio recorded the answers, and later the answers were transcribed.

$$
\begin{aligned}
& \text { Researcher: Qu'est-ce que tu fais } \\
& \text { le soir? } \\
& \text { what you do-PRS } \\
& \text { the evening }
\end{aligned}
$$

\begin{tabular}{|c|c|c|}
\hline un & $\begin{array}{l}\text { Participant: } \\
\text { roman le }\end{array}$ & $\begin{array}{l}\text { Je lis-PRS toujours } \\
\text { soir. }\end{array}$ \\
\hline evening & I read always & novel the \\
\hline
\end{tabular}

'What do you do in the evening?'
'I always read a novel in the evening?'

\section{RESULTS}

\section{Acceptability judgement task}

As mentioned previously, the judgments of the participants were measured on a five-point Likert scale of -2 to +2 . The endpoints were defined as unacceptable and acceptable. The acceptability judgment task tested two conditions: *SAdv-V-O and S-V-Adv-O. The descriptive statistics are reported in table 4 . The native speakers showed a strong distinction between the grammatical and ungrammatical conditions. They had a high mean rating for the grammatical 
structure $(M=1.82, S D=0.20)$, and a low mean rating for the ungrammatical structure $(M=-1.70, S D=0.33)$. The paired sample $t$-test was conducted for the two conditions. The result was statistically significant $(t(7)=24.1, p=001)$.

In contrast to the native speakers, the non-native speakers did not demonstrate a strong differentiation between the grammatical and ungrammatical conditions. They attributed a low mean rating to the grammatical condition $(M=0.72$, $S D=0.55)$, while their mean rating for the ungrammatical structure was high $(M=0.30, S D=0.72)$. The paired sample $t$ test was conducted for the two conditions. In contrast to the native speakers, the paired sample $t$-test result was not statistically significant for the two structures $(t(11)=1.28$, $p=228$ ).

Table 4. Audio AJT mean ratings on S-V-Adv-X versus *S-Adv-V-X (scale $=\mathbf{- 2 - + 2}$ )

\begin{tabular}{llll}
\hline Group & Word order & Mean & SD \\
\hline L1 French & S-V-Adv-O & 1.82 & 0.20 \\
& *S-Adv-V-O & -1.70 & 0.33 \\
L2 French & & & \\
& S-V-Adv-O & 0.72 & 0.55 \\
& *S-Adv-V-O & 0.30 & 0.72 \\
\hline
\end{tabular}

\section{Preference Task}

Twenty experimental tokens and ten fillers were included in the Preference task. Similar to the AJT, the preference task tested two structures: *S-Adv-V-O and S-V-Adv-O. The participants were presented with two sentences that differed only in syntactic form. They were asked to choose a sentence that they preferred. However, the answer grid was organized in a way that the participants could accept or reject both sentences, or they also had the freedom to choose the option that both sentences are not relevant. Table 5 reports the S-V-Adv-O and *S-Adv-V-O choices in percentages. Both groups showed a strong preference for the S-V-Adv-O structure. However, unlike the native speakers, the non-native also accepted the ungrammatical S-Adv-V-O structure. Figure 3 illustrates the data presented in table 5.

Table 5. Preference Task- S-V-Adv-O and ${ }^{*} \mathrm{~S}-\mathrm{Adv}-\mathrm{V}-\mathrm{O}$ choices in percentages

\begin{tabular}{lrr}
\hline & L2 French & L1 French \\
\hline S-V-Adv-V-O & 65 & 99 \\
$*^{*}$ S-Adv-V-O & 23 & 01 \\
a) and b) are equally good or bad & 10 & 00 \\
Neither a) nor b) & 02 & 00 \\
\hline
\end{tabular}

\section{Figure 3. S-V-Adv-O and *S-Adv-V-O choices in percentages by groups}

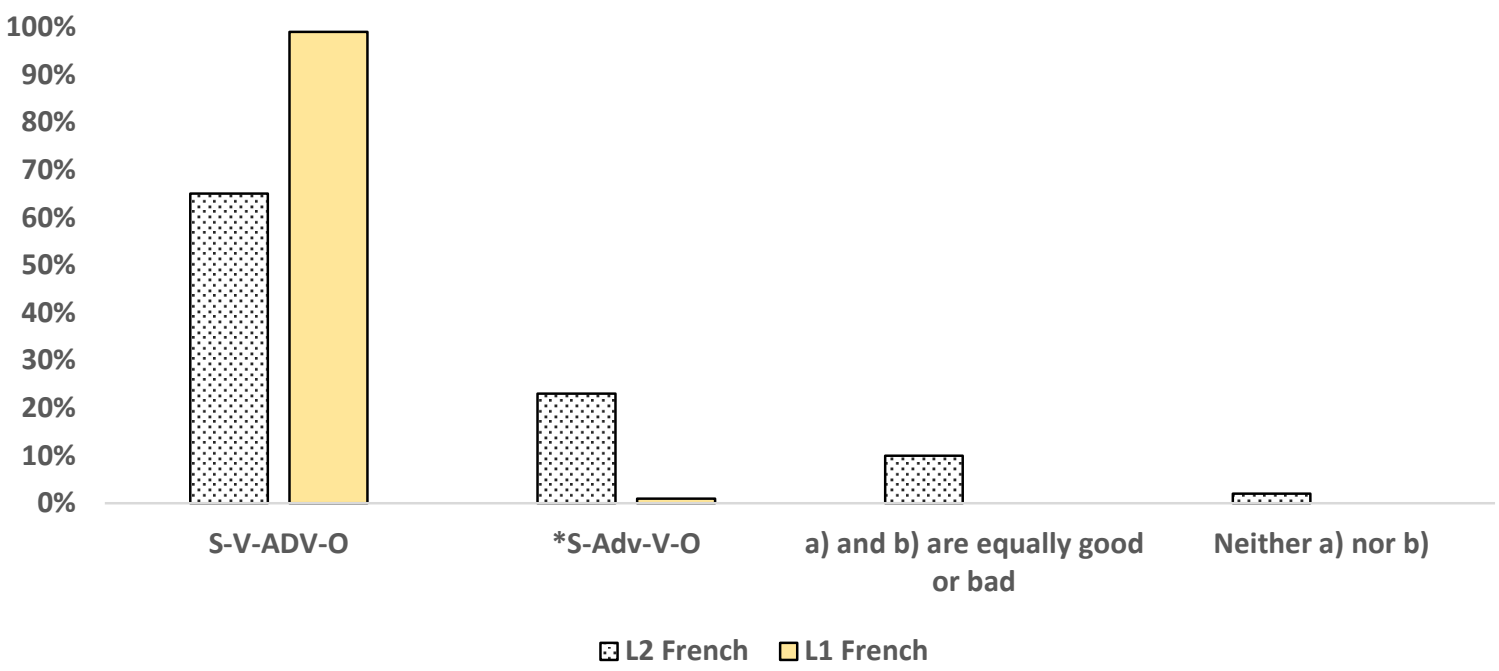

\section{Production Task}

The participants were free to use any structure, and they used three structures: S-V-Adv-O, *S-Adv-V-O, and S-V-OAdv. However, the Adv-S-V-O structure was not produced by any participant. The non-native speakers used the S-V-OAdv structure, whereas none of the native speakers used this structure. Further, the non-native group looks very different from the native group. Unlike the native speakers, the non-native speakers predominantly used the ungrammatical S-Adv-V-O structures (42\%), and they used grammatical S-VAdv-O less frequently (35\%). Table 6 reports the S-V-Adv-O, *S-Adv-V-O, and S-V-O-Adv choices in percentages. Figure 4 illustrates the data presented in table 6. 
Table 6. S-V-ADV-O, S-Adv-V-O, and S-V-O-Adv choices in percentages

\begin{tabular}{lll}
\hline & L2 French & L1 French \\
\hline S-V-Adv-O & 35 & 100 \\
$*$ S-Adv-V-O & 42 & 00 \\
S-V-O-Adv & 23 & 00 \\
\hline
\end{tabular}

Figure 4. Percentage of each structure produced by groups

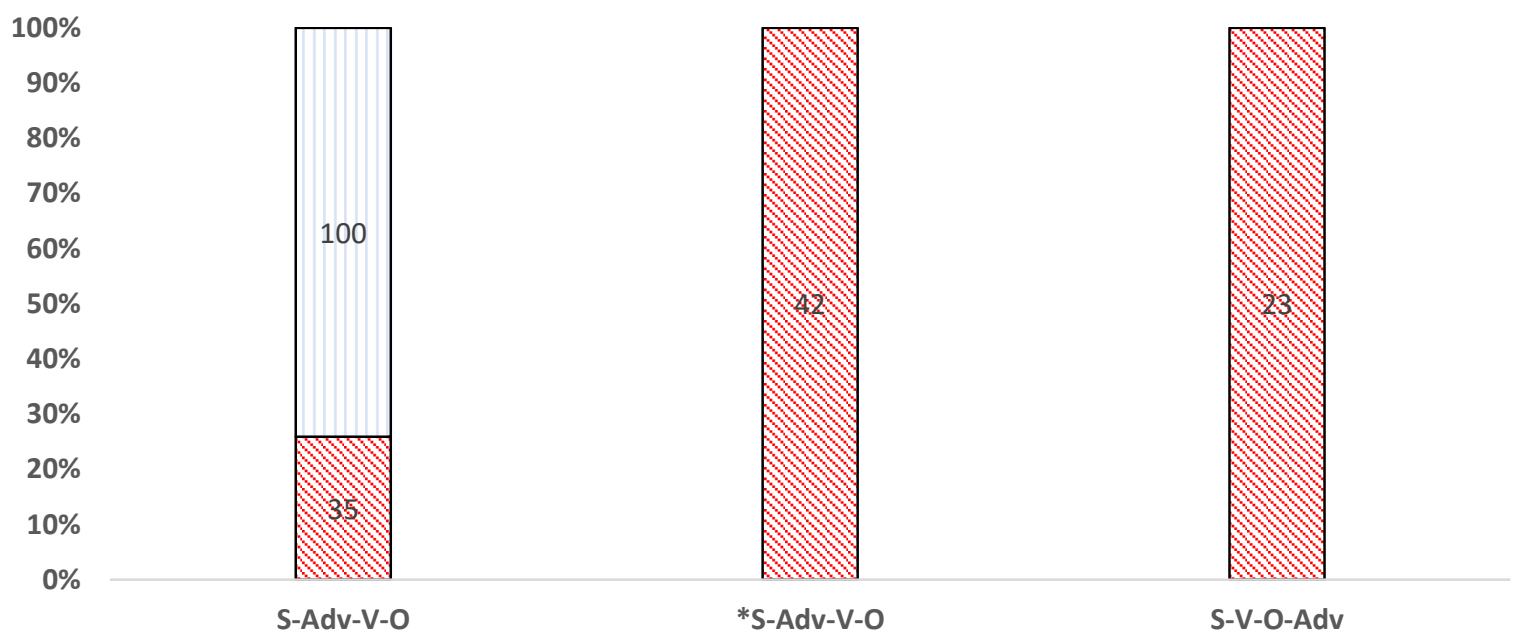

Q L2 French $\square$ L1 French

\section{DISCUSSION}

As indicated previously, the present paper tested two influential models: the FFFH and the FTFAH. Let us now recall the predictions made by these models. The FFFH maintains that L2 speakers do not have access to UG, and they fail to reset parameters in L2 acquisition after the critical period, whereas the FTFAH claims that L2 speakers have access to UG, and they can reset parameters after the critical period. As noted in section 5, the two hypotheses tested in the presented study are formulated concerning the FFFH and the FTFAH. I now examine the hypotheses in relation to the results before concluding which of the two $L 2$ models best fits, if any.

Hypothesis 1: L2 French adverb placement under the FFFH If Hypothesis 1 is correct, I predict that the non-native speakers will assume that the L1 parameter settings are appropriate for their L2, and the non-native speakers will reject the grammatical S-V-Adv-O structure in French. On the contrary, they will accept the ungrammatical S-Adv-V-O structure.

Let us now consider Hypothesis 1 in relation to the results of the three tasks. The AJT results showed that the native speakers distinguish between the grammatical and ungrammatical conditions. However, the non-native speakers attributed a low mean rating to the grammatical condition $(\mathrm{M}=0.72, \mathrm{SD}=0.55)$, while their mean rating for the ungrammatical structure was high $(M=0.30, S D=0.72)$. The inferential statistics showed that the non-native speakers do not differentiate between the grammatical and ungrammatical structures. Turning to the preference task, the non-native speakers preferred the grammatical structure $(65 \%)$, which shows that they performed at the above chance level on adverb placement in this task. The results also showed that the non-native speakers are comparable to the native speakers in this task. Turning to the production task, the non-native speakers predominantly used the ungrammatical S-Adv-V-O structure $(42 \%)$, which shows that their performance is not above chance level.
In sum, the preference task results do not entirely support the FFFH. However, the results of the AJT and the production, taken together, show that the non-native speakers had not fully acquired the grammatical adverb placement in French. Thus, the results are compatible with the FFFH.

Hypothesis 2: L2 French adverb placement under the FTFAH

If the FTFAH is correct, I predict that the non-native speakers will reset the L1 parameters, and they will reject the ungrammatical S-Adv-V-O structure in French. As noted in the previous section, the AJT and the production task results demonstrated that the non-native speakers rated the *SAdv-V-O structure higher than the S-V-Adv-O structure, and they used the ungrammatical structure more frequently than the grammatical structure in their responses. However, in the preference task, they showed a strong preference for the S-V-Adv-O structure. Further, the preference task results suggest that the non-native speakers have reset their verb raising parameter to a certain extent. However, the FTFAH is not entirely supported by the results.

I suggest that the results of the AJT and the Production task, taken together, can be squared with the FFFH. This suggests that the non-native speakers have not reset their parameters in L2 French, and they would assume that the L1 parameter settings are appropriate for their $L 2$. Similar results have been reported by other $\mathrm{L} 2$ acquisition studies.

\section{RESEARCH QUESTIONS}

The present study examines the following research questions:

\section{Research Question 1:}

What are the characteristics of adverb placement in L2 French by L1-English speakers?

\section{Research Question 2:}

To what extent can either the FFFH or the FTFAH account for L2 French characteristics? 
Turning to Research Question 1, the results show that the characteristics of adverb placement in L2 French differ greatly from that of the French native speakers. The $L 2$ speakers accepted and used both grammatical and ungrammatical structures in French. Therefore, the results suggest that both structures co-exist in their interlanguage.

Turning to Research Question 2, as discussed previously, the results are compatible with the FFFH. This question is further discussed in the following section.

\section{CONCLUSION}

As noted earlier, White (1991) investigated the knowledge of adverb placement in L2 English by native French speakers. White (1991) predicted that the French-speaking L2 English learners would accept the ungrammatical S-V-Adv-O structure in English as they would assume that L1 parameter settings are appropriate for their $\mathrm{L} 2$. The overall results showed that her learners accepted both grammatical and ungrammatical adverb placement. Therefore, this study also provides substantial evidence to support the FFFH.

As discussed previously, Rogers (2009) also reports similar results. She investigated the adverb placement in L2 French and collected data via three tasks: an oral production task, a comprehension task, an acceptability judgement task. In the production task, the French native speakers predominantly used the S-V-Adv-O structure. However, the L2 French speakers used the S-V-Adv-O structure less frequently in their production. Most importantly, the L2 speakers also used preverbal adverb placement ( $\left.{ }^{*} S-A d v-V-O\right)$. The comprehension task results, again, showed that learners have not fully acquired the grammatical adverb placement. The AJT results showed that the acceptance of the ungrammatical structure (S-Adv-V-O) decreases with French proficiency. The overall AJT results suggest that, except for advanced groups, the adverb placement seems to be problematic for all other groups.

Therefore, it is reasonable to argue that the results of this study are similar to that of White (1991) and Rogers (2009). Further, I argue that the adult L2 French speakers in the present paper had not acquired the verb movement parameter in French. Other syntactic properties, like negation and object clitics, are also linked to the verb movement parameter (Borer 1983; Kayne, 1975; Rowlett, 2007; Sportische, 1996). Therefore, we could assume that acquiring these properties (negation and object clitics) would also be problematic for L2 French speakers.

Further, the overall results support the assumptions of the $\mathrm{FFFH}$ and suggest that the verb movement parameter is inaccessible for adult $\mathrm{L} 2$ learners (beyond the critical period) who are at the intermediate and upper-intermediate levels. Based on the results, we could also assume that acquiring negation and object clitics would also be problematic for L2 French. This topic has been discussed in a few research papers (Grüter \& Crago, 2011; Grüter, 2005,2009; Gunawardena, 2018; Hamann et al.,1996). However, most of the studies test learners at the initial stage of $L 2$ French acquisition. Therefore, Future research would need to test learners at a higher level of proficiency to determine whether the verb movement parameter is eventually reset to its appropriate $L 2$ value, and also to determine whether $L 2$ learners could eventually acquire other properties (negation and object clitics) associated with the verb movement parameter.

\section{References}

Adger, D. (2003). Core Syntax: A minimalist approach. New York: Oxford University Press.

Bley-Vroman, R. (1998). Access to UG: Can we have our cake and eat it too? Colloquium presentation at the Second Language Research Forum, Honolulu, Hawaii.

Borer, H. (1983). Parametric syntax, case studies in Semitic and Romance languages. Foris: Dordrecht.

Chomsky, N. (1989). Some notes on Economy of Derivation and Representation.

Chomsky, N. (2000). New horizons in the study of language and mind. Cambridge: Cambridge University Press.

Clahsen, H. (1988). Parameterized grammatical theory and language acquisition: A study of the acquisition of the verb placement and inflection by children and adults. In S. Flynn \& W. O'Neil (Eds.), Linguistic theory in Second Language Acquisition (pp. 47-75). Dordrecht: Kluwer.

Clahsen, H., \& P. Muysken (1986). The availability of universal grammar to adult and child learners. A study of the acquisition of German word order. Second Language Research 2(3), 93-119.

Emonds, J. (1978). The verbal Complex V'-V in French. Linguistic Inquiry, 9(1), 151-75.

Eubank, L. (1994). Optionality and the initial state in L2 development. In T. Hoekstra \& B. Schwartz (Eds.), Language acquisition studies in Generative Grammar (pp. 369-388). Amsterdam, Philadelphia: John Benjamins.

Grüter, T. \& Crago, T. (2011). Object clitics and their omission in child L2 French: the contributions of processing limitations and L1 transfer. Bilingualism: Language and Cognition, 15(3), 531-549.

Grüter, T. (2005). Comprehension and production of French object clitics by child second language learners and children with specific language impairment. Applied Psycholinguistics, 26(2), 363-391.

Grüter, T. (2006b). object clitic omission in L2 French: Mis-setting or missing surface inflection? In M. Grantham O'Brien, C. Shea \& J. Archibald (Eds), Proceedings of the $8^{\text {th }}$ Generative Approaches to Second Language Acquisition Conference (GASL 2006), (pp 63-71). Somerville, MA: Cascadilla Proceedings Project.

Grüter, T. (2009). A unified account of object clitics and referential null objects in French. Syntax, 12 (3), 215-241.

Grüter, T., \& Crago, T. (2011). Object clitics and their omission in child L2 French: The contributions of processing limitations and L1 transfer. Bilingualism: Language and Cognition, 15(3): 531-549, Cambridge University Press.

Gunawardena. C. (2018). Object clitics in French second language acquisition. ConSOLE XXVI Proceedings, University of Leiden.

Hamann, C., Rizzi, L., \& Frauenfelder, U. (1996). On the acquisition of subject and object clitics in French. In H. Clahsen (Ed.). Generative perspectives on language acquisition (pp. 309-334). Amsterdam: John Benjamins.

Hawkins, R., \& Chan, C. (1997). The partial availability of Universal Grammar in Second Language Acquisition: The failed functional features hypothesis. Second Language Research, 13(3), 187-226.

Marsden, H., Whong, M., \& Gil, K.H. (2018). What's in the Textbook and What's in the Mind: Polarity Item "Any" in Learner English. Studies in Second Language Acquisition, 40 (1), 91-118.

Meisel, J. (1991). Principles of Universal Grammar and strategies of language use: On some similarities and differences between first and second language acquisition. In L. Eubank (Ed.), Universal Grammar in the second language (pp. 231-276). Amsterdam, Philadelphia: John Benjamins.

Meisel, J. (1997). The acquisition of the syntax of negation in French and German: Contrasting first and second language acquisition. Second Language Research, 13(3), 227-263.

MIT Working Papers in Linguistics, 10, 43-74.

Mitchell, R., \& Myles, F. (1998). Second language learning theories. London: Arnold.

Peirce, J. W. (2007). PsychoPy-Psychophysics software in Python. Journal of Neuroscience Methods, 162, 8-13.

Pollock, J. (1989). Verb movement, Universal Grammar, and the structure of IP. Linguistic Inquiry, 20(3), 365-425. 
Rogers, V. (2009). Syntactic development in the second language acquisition of French by instructed English learners (Unpublished doctoral dissertation). Newcastle University, Newcastle.

Rowlett, P. (2007). The syntax of French. Cambridge Syntax guides. Cambridge: Cambridge University Press.

Schwartz, B. D., \& Sprouse, R. (1994). Word order and nominative case in non-native language acquisition: A longitudinal study of (L1 Turk ish) German interlanguage. In T. Hoekstra \& B. D. Schwartz (Eds.). Language acquisition studies in generative grammar (pp. 317-368). Amsterdam: Benjamins.

Schwartz, B., \& Sprouse, R. (1996). L2 cognitive states and the full transfer/full access model. Second Language Research, 12(1), 40-72.

Sportiche, D. (1992). Clitic Construction. In J. Rooryck \& L. Zaring (Eds), Phrase Structure and the Lexicon (pp. 213-276). Kluwer: Dordrecht.

Vainikka, A., \& Young-Scholten, M. (1996). The gradual development of L2 the phrase structure. Second Language Research, 12(1), 7-39.

White, L (1996). Clitics in L2 French. In H. Clahsen (Ed.), Generative perspectives on language acquisition: Empirical findings, theoretical considerations, and cross-linguistic comparisons (pp. 335-368). Philadelphia, PA: John Benjamins Publishing.

White, L. (1991). The Verb-Movement Parameter in Second Language Acquisition. Language Acquisition, 1(4), 337-360.

White, L. (2003). Second Language Acquisition and Universal Grammar Cambridge Textbooks in Linguistics. Cambridge University Press, Cambridge. 